\title{
ANÁLISE DA SENSIBILIDADE DE UM MODELO DE ATENUAÇÃO ESPECTRAL DA IRRADIÂNCIA NA ATMOSFERA EM DIFERENTES CONDIÇÕES ATMOSFÉRICAS: UMA APLICAÇÃO PARA 0 Sea-viewing Wide Field-of-view Sensor (SeaWiFS)
}

\author{
Claudia Yuki Omachi, 'Carlos Alberto Eiras Garcia² \\ Recebido em 2 out. 2003 / Aceito em 9 jun. 2004 \\ Received oct. 2, 2003 / Accepted jun. 9, 2004
}

\begin{abstract}
A sensitivity analysis of an irradiance spectral attenuation model is performed by varying three atmospheric parameters: total ozone, visibility and total precipitable water. The incident solar spectral irradiance over the sea surface is calculated at the Sea-viewing Wide Field-of-view Sensor (SeaWiFS) bands for remote sensing applications. The effects of these atmospheric parameters over some remote sensing reflectance ratios usually used for mapping chlorophyll a concentration from the space are also assessed. The results have shown that visibility is the most important parameter which exerts influence on modeled spectral irradiance but its effect on the remote sensing ratios is smaller than that from total ozone. The total precipitable water did not alter both modeled spectral irradiances and remote sensing ratios for solar zenith angles smaller than $60^{\circ}$. No significant differences were found when solar zenith angles varied from 0 and $60^{\circ}$, even when we used extremely high values of atmospheric parameters. For remote sensing reflectance band ratios 490/510, 490/555 and 510/555 under solar zenith angles smaller than $60^{\circ}$, average values of these atmospheric parameters tested here are enough to model irradiance band ratios.
\end{abstract}

Keywords: irradiance, ocean color, model, atmosphere, SeaWiFS

\section{RESUMO}

A sensibilidade de um modelo de irradiância espectral, incidente sobre a superfície do mar, variando três parâmetros atmosféricos (ozônio, visibilidade e vapor de água precipitável), é analisada, com especial ênfase para as bandas do sensor Sea-viewing Wide Field-of-view Sensor (SeaWiFS). São também analisadas as razões entre bandas de reflectância geralmente utilizadas nos algoritmos bio-óticos, para mapeamento da biomassa fitoplanctônica do espaço. Os resultados mostram que a visibilidade é o parâmetro que mais causa alteração nos valores de irradiância, embora o seu efeito nas razões entre bandas seja menor do que 0 efeito do ozônio. 0 vapor de água precipitável não causou alteração significativa nem nas irradiâncias e nem nas razões entre bandas. Os valores extremos destes parâmetros não causaram diferenças significativas para ângulos solares entre 0 e 60\%. Para se obter a razão entre reflectâncias das bandas 490/510, 490/555 e $510 / 555$ em ângulos solares menores que $60^{\circ}$, valores médios destes parâmetros atmosféricos testados neste trabalho são suficientes para se modelar a razão entre irradiâncias.

Palavras-chave: irradiância, cor do oceano, modelo, atmosfera, SeaWiFS

\footnotetext{
Lab. Estudos sobre Algas Nocivas - CTTMar / UNIVALI - Rua Uruguai, 458 - 88302-202 Itajaí - SC -Tel. +55 473417719 Fax +55 473417715 - E-mail: comachi@cttmar.univali.br UFRGS - Universidade Federal do Rio Grande do Sul - Av. Bento Gonçalves, 9500 - Campus do Vale - Caixa Postal 15044 - CEP $91501-970$ - Porto Alegre - RS - Tel. + 55473417719 Fax +55473417715-E-mail: c omachi@yahoo.com.br

2 Setor de Oceanografia Física - Departamento de Física - FURG - Av. Itália, Km 8 Campos Carreiros - Caixa Postal 474 - CEP 96201-900 - Rio Grande - RS - Tel + 55(53)233-6888 Fax: +55(53)233-6652 -E-mail: dfsgar@furg.br
} 


\section{INTRODUÇÃOO}

Estimativas recentes (BEHRENFELD et al., 2001) mostram a relevância do papel do fitoplâncton marinho no ciclo global do carbono, como um importante seqüestrador de carbono atmosférico. Além disso, 0 conhecimento desta biomassa é de extrema relevância para estudos de ecossistemas costeiros e oceânicos, pois o fitoplâncton compõe 0 inicio da cadeia trófica nesses sistemas. Assim sendo, enormes esforços vêm sendo despendidos pelas agências espaciais, no sentido de mapear do espaço a biomassa desses produtores primários, através do lançamento de vários sensores remotos da cor do oceano.

A influência do fitoplâncton na variação da cor do oceano vem sendo estudada há várias décadas. 0 estudo pioneiro de Clarke, Ewing e Lorenzen (1970) mostrou claramente que, para altas concentrações de fitoplâncton marinho, o espectro da luz solar retroespalhada apresentava-se muito mais esverdeado do que em baixas concentrações. Dessa forma, quantificando e monitorando a variação da cor do oceano, poder-se-ia obter uma estimativa da concentração de biomassa fitoplanctônica.

Baseado nesta hipótese, no final da década de 1970 foi lançado o primeiro sensor remoto voltado ao monitoramento da cor do oceano, 0 Coastal Zone Color Scanner (CZCS), pela National Aeronautics and Space Administration (NASA). Esse sensor era dotado de quatro bandas na fração visível do espectro eletromagnético, centradas em 443, 520, 550 e $670 \mathrm{~nm}$ de comprimento de onda, e com resolução radiométrica de 8 bits (HOVIS et al., 1980). Como em águas oceânicas (portanto, distante do aporte continental) o maior contribuinte na variação da cor do oceano é o fitoplâncton, os dados obtidos pelo CZCS foram usados com sucesso para estimar a concentração da biomassa fitoplanctônica nessas regiōes. 0 CZCS funcionou entre 1978 e 1986, gerando um grande volume de dados de escala sinóptica, que permitiu aprofundar 0 conhecimento da distribuição espacial do fitoplâncton marinho numa escala que investigações pontuais realizadas a bordo de navios jamais conseguiriam fornecer (MITCHELL, 1994).

Após uma década sem informações sinópticas da cor do oceano, nova geração de sensores, com melhor resoluçã̃o espectral e radiométrica, foi colocada em órbita no espaço. Em agosto de 1996, o satélite Advanced Earth Observation System (ADEOS) foi lançado pela National Space Development Agency of Japan (NASDA), levando a bordo dois sensores da cor do oceano: Ocean Color and Temperature Scanner (OCTS) e Polarization and Directionality of the Earth's Reflectances (POLDER). 0 satélite ADEOS esteve em funcionamento até junho de 1997, quando por problemas técnicos, parou de funcionar. Em setembro de 1997, 0 sensor Sea-viewing Wide Field-of-view Sensor (SeaWiFS) da NASA foi lançado, com seis bandas na faixa visível do espectro eletromagnético.
As bandas são centradas em 412, 443, 490, 510,555 e $670 \mathrm{~nm}$ com $20 \mathrm{~nm}$ de largura e 10 bits de resolução radiométrica. Esta melhoria radiométrica, acompanhada de um planejamento de coleta de dados bio-óticos em diversas regiões oceânicas e costeiras, permitiria estimativas mais acuradas da concentração de clorofila a do espaço. Nos últimos anos, o sensor Moderate Resolution Imaging Spectroradiometer(MODIS) lançado a bordo dos satélites Terra (EOS AM) e Aqua (EOS PM), em dezembro de 1999 e maio de 2002, respectivamente, fornece, juntamente com o SeaWiFS, visões sinópticas de processos oceânicos em diferentes escalas de espaço e tempo, além de imagens da biomassa fitoplanctônica - base da cadeia alimentar nos oceanos. 0 instrumento MODIS possui alta sensibilidade radiométrica (12 bit) e opera em 36 bandas espectrais, com comprimento de onda variando entre $400 \mathrm{~nm}$ e $1440 \mathrm{~nm}$. Os canais de 8 a 14 estão na faixa da radiação visível compreendida entre 405 - 420, 438 - 448, 483 - 493, 526 - 536, 546 556, 662 - 672 e 673 - $683 \mathrm{~nm}$, respectivamente. Há, portanto, muita similaridade entre as bandas na faixa do visivel dos sensores SeaWiFS e MODIS.

A relaçã̃o entre a radiação espectral solar emergente da água do mar e a concentração superficial da biomassa fitoplanctônica (concentração de clorofila a) é comumente conhecida por algoritmo bio-ótico. Os algoritmos bio-óticos empíricos, no momento mais eficientes que os semi-analíicicos, são bastante usados na estimativa da concentração de pigmentos fitoplanctônicos, e geralmente utilizam a razão entre as bandas de máxima (443 e 490nm) e mínima (510 e 555nm) absorção do fitoplâncton. A utilização de razões entre reflectância espectral, ao invés de outro tipo de combinação - diferença, por exemplo - está alicerçada no fato de que as grandezas radiância e reflectância espectral são diretamente sensíveis aos processos de retroespalhamento e absorção, de forma que podem variar por um fator de 2 ou mais, para um determinado valor de concentração de clorofila $a$, enquanto que as razões entre estas grandezas espectrais permanecem praticamente invariantes. Há também que se considerar que 0 caráter da bidirecionalidade da reflectância dos oceanos é extremamente reduzido ao se utilizar as razões. Outro fator relevante é a metodologia utilizada no processamento das imagens, no sentido de corrigir os efeitos atmosféricos das imagens. 0 uso das razões também reduz sensivelmente esses efeitos atmosféricos (INTERNATIONAL OCEAN..., 1998). Assim, em diversas regiões do mundo, investigações vêm sendo conduzidas no sentido de se construírem algoritmos empiricos regionais consistentes3, cujos dados bio-óticos possam contribuir na elaboração de um modelo global robusto (0'REILlLY et al., 1998).

0 desenvolvimento de algoritmos empíricos requer medições simultâneas de radiâncias espectrais emergentes do oceano, irradiância espectral descendente no oceano e concentração superficial de clorofila 
a. As informações radiométricas são requeridas para estabelecer a relação entre a razão entre reflectâncias $\left(R_{i j}\right)$ de dois comprimentos de onda e a concentração superficial de pigmentos fitoplanctônicos $(C)$ :

$R_{i j}=f(C)$,

onde $R_{i j}$ é obtida pela razão entre reflectância das bandas $\lambda_{i}$ e $\lambda_{j}$ :

$$
R_{i j}=\frac{\operatorname{Rrs}\left(\lambda_{i}\right)}{\operatorname{Rrs}\left(\lambda_{j}\right)},
$$

sendo $\operatorname{Rrs}(\lambda)$ a reflectância de sensoriamento remoto na banda $\lambda$, isto é

$$
\operatorname{Rrs}(\lambda)=\frac{L_{w}(\lambda)}{E_{d}(\lambda)} .
$$

Na Equação $3, L_{w}(\lambda)$ é a radiância espectral emergente da superfície do mar na banda $\lambda$ e $E_{d}(\lambda)$ é a irradiância espectral descendente sobre a superfície do mar no comprimento de onda $\lambda$.

Essas grandezas ópticas aparentes, $L_{w}(\lambda)$ e $E_{d}(\lambda)$, devem ser medidas in situ, simultaneamente às determinações de concentração superficial de clorofila $a$. Entretanto, inúmeras dificuldades impossibilitam a coleta de $L_{w}(\lambda)$, que deveria ser medida acima da superfície do mar. Entre elas, destaca-se a contaminação da reflexão da luz direta e difusa pela superfície do mar. Como a maioria dos instrumentos óticos utilizados em oceanografia mede a radiação espectral na faixa do visível no interior da coluna de água, a final das medições obtém-se a radiância ascendente na coluna de água do mar, $L_{u}(\lambda, z)$. Conhecendo-se esta grandeza, a diferentes profundidades, a irradiância logo abaixo da superfície do mar, $L_{u}\left(\lambda, 0^{-}\right)$pode ser estimada por regressão linear e, assim permitir a determinação de $L_{w}(\lambda)$ através de

$$
\operatorname{Rrs}(\lambda)=\frac{L_{w}(\lambda)}{E_{d}(\lambda)}=\frac{t}{n^{2}} \frac{L_{u}\left(\lambda, 0^{-}\right)}{E_{d}(\lambda)}
$$

onde $t$ e $n$ representam a transmitância e 0 índice de refraçãa da água do mar, respectivamente. No caso, o termo $t / n^{2} \approx 0.54$ representa o fator de transmissão da radiância espectral através da interface água-ar, que depende fracamente do comprimento de onda e praticamente invariante para a velocidade do vento (AUSTIN, 1974).

A irradiância espectral descendente sobre a superfície do mar, $E_{d}(\lambda)$, pode ser medida com instrumentos óticos adequados ou estimada por modelos simplificados de atenuação da irradiância espectral na atmosfera (GREGG; CARDER, 1990). No entanto, esta estimativa por modelagem depende de parâmetros e constituintes atmosféricos, nem sempre fáceis de serem obtidos em oceano aberto. Como exemplo, Gregg e Carder (1990) apontam que a visibilidade, o vapor de água precipitável e a concentração de ozônio podem causar desvios percentuais acima de $12 \%$ nas estimativas da irradiância.

Tendo em vista a dificuldade de obtenção de parâmetros atmosféricos com a frequiência desejada, o presente trabalho tem como objetivo analisar a influência da visibilidade, do vapor de água precipitável e da concentração de ozônio na estimativa da irradiância espectral descendente na superfície do oceano. Esta análise será efetuada para as bandas do SeaWiFS, e nas razões entre as bandas mais usadas nos principais algoritmos empíricos para a determinaçã̃o da concentração superficial de clorofila $a$. Os resultados obtidos permitirão aferir a importância dos parâmetros atmosféricos sobre as propriedades óticas aparentes na coluna de água do mar e, principalmente, a importância de se medir a radiância espectral descendente sobre a superfície do mar quando da elaboração de algoritmos bio-óticos para mapeamento da biomassa fitoplanctônica do espaço.

\section{MATERIAL E MÉTODOS}

\section{0 modelo da irradiância espectral}

0 modelo usado para estimar a irradiância espectral descendente sobre a superfície do mar foi adaptado de Gregg e Carder (1990). Esse modelo calcula a atenuação espectral da irradiância na fração da radiação disponível para a fotossíntese, mais comumente conhecida como PAR (Photosynthetically Available Radiance), compreendida entre 400 e $700 \mathrm{~nm}$ de comprimento de onda, na forma:

$$
\operatorname{PAR}(\theta)=\int_{400}^{700}\left[E_{d d}(\theta, \lambda)+E_{d s}(\theta, \lambda)\right] d \lambda,
$$

onde $\theta$ é 0 ângulo solar zenital (formado pela direçã̃o do Sol e a reta normal à superfície), $\lambda$ é 0 comprimento de onda, $E_{d d}(\theta, \lambda)$ e $E_{d s}(\theta, \lambda)$ são as componentes direta e difusa da irradiância espectral descendente $\left(W^{-2} \mathrm{~nm}^{-1}\right)$. A resoluçã̃o espectral $d \lambda$ do modelo é de 1 nm. 0 ângulo $\theta$ foi determinado usando a equação de Kirk (1994):

$$
\operatorname{sen}\left(90^{\circ}-\theta\right)=\operatorname{sen} \gamma \operatorname{sen} \delta-\cos \gamma \cos \delta \cos \tau,
$$

onde $\gamma$ é a latitude local, $\delta$ é a declinação solar (SPENCER, 1971) e $\tau$ é a hora do dia em graus.

As componentes direta e difusa da irradiância espectral descendente foram calculadas separadamente:

$E_{d d}(\theta, \lambda)=F_{0}(\lambda) \cos \theta T_{r}(\lambda) T_{a}(\lambda) T_{o z}(\lambda) T_{o}(\lambda) T_{w}(\lambda)$ 
$E_{d s}(\theta, \lambda)=E_{r}(\theta, \lambda)+E_{a}(\theta, \lambda)$,

onde $F_{0}(\lambda)$ é a irradiância extraterrestre média corrigida para a excentricidade orbital e para a distância Sol-Terra; $T_{i}(\lambda)$ são as transmitâncias de cada componente atmostérico. $E_{r}$ e $E_{a}$ são as componentes da irradiância difusa devido, respectivamente, a espalhamentos Rayleigh e de aerossóis que são calculadas por:

$$
\begin{aligned}
& E_{r}(\theta, \lambda)=F_{0}(\lambda) \cos \theta T_{o z}(\lambda) T_{o}(\lambda) \\
& T_{w}(\lambda) T_{a a}(\lambda)\left[1-T_{r}(\lambda)^{0,95}\right] \times 0,5 \\
& E_{a}(\theta, \lambda)=F_{0}(\lambda) \cos \theta T_{o z}(\lambda) T_{o}(\lambda) \\
& T_{w}(\lambda) T_{a a}(\lambda) T_{r}(\lambda)^{1,5}\left[1-T_{a s}(\lambda)\right] \times F_{a},
\end{aligned}
$$

onde $F_{a}$ é a probabilidade da irradiância ser espalhada para frente pelo aerossol.

A transmitância devido ao espalhamento Rayleigh, $T_{r}(\lambda)$, foi calculada segundo Bird e Riordan (1986):

$$
T_{r}(\lambda)=\exp \left[-\frac{M^{\prime}(\theta)}{115,6406 \lambda^{4}-1,335 \lambda^{2}}\right],
$$

onde $M^{\prime}(\theta)$ é 0 comprimento do caminho atmosférico, $M(\theta)$, corrigido pela relação entre a pressão atmosférica local $(P)$ e a pressão atmosférica padrão $\left(P_{0}\right) \cdot M(\theta)$ é requerido no cálculo da transmitância atmosférica devido à atenuação por todos os constituintes e foi calculada como em Kasten (1966):

$$
M(\theta)=\frac{1}{\cos \theta+0,15(93,885-\theta)^{-1,253}} .
$$

por:

$$
T_{o z}(\lambda)=\exp \left[-a_{o z}(\lambda) H_{o z} M_{o z}(\theta)\right],
$$

onde $a_{o z}(\lambda)$ é o coeficiente de absorção do ozônio, $H_{o z}$ é a escala de altura do ozônio e $M_{o z}(\theta)$ é 0 comprimento do caminho atmostérico corrigido para 0 ozônio, descrito por Paltridge e Platt (1976) como:

$$
M_{o z}(\theta)=\frac{1,0035}{\left(\cos ^{2} \theta+0,007\right)^{0,5}} .
$$

A transmitância após absorção e espalhamento pelos aerossóis, $T_{a}(\lambda)$, é dada por:

$$
T_{a}(\lambda)=\exp \left[-\tau_{a}(\lambda) M(\theta)\right],
$$

onde $\tau_{a}(\lambda)$ é a camada óptica do aerossol como calculada em Gregg e Carder (1990) em função da visibilidade, sendo usada em todas as transmitâncias devido a a aerossol. Assim, as transmitâncias somente do espalhamento (sem absorção) pelo aerossol, $T_{a s}(\lambda)$, e somente da absorção (sem espalhamento) pelo aerosol, $T_{a a}(\lambda)$, também são dadas em função da visibilidade.

A transmitância devido à absorção pelo oxigênio, $T_{0}(\lambda)$, foi calculada como em Bird e Riordan (1986), em função do coeficiente de absorção pelo oxigênio, $a_{0}(\lambda)$ :

$$
T_{o}(\lambda)=\exp \left\{\frac{-1,41 a_{o}(\lambda) M^{\prime}(\theta)}{\left[1+118,3 a_{o}(\lambda) M^{\prime}(\theta)\right]^{0,45}}\right\} ;
$$

A transmitância devido à absorção pelo vapor de água, $T_{w}(\lambda)$, foi calculada pela equação (BIRD; RIORDAN, 1986):

$$
T_{w}(\lambda)=\exp \left\{\frac{-0,2385 a_{w}(\lambda) V A M(\theta)}{\left[1+20,07 a_{w}(\lambda) V A M(\theta)\right]^{0,45}}\right\} ;
$$

onde $a_{w}(\lambda)$ é o coeficiente de absorção do vapor de água e $V A$ é 0 vapor de água precipitável.

\section{Sensibilidade do modelo nas bandas do SeaWiFS}

Para analisar a influência que os parâmetros de entrada do modelo podem exercer na estimativa da irradiância espectral das bandas do sensor SeaWiFS, foram analisadas sete situações meteorológicas para 10 diferentes ângulos solares zenitais $(\theta=5,10,20,30,40,50,60$, 70,80 e $85^{\circ}$ ) para a cidade de Rio Grande $\left(32,02^{\circ} \mathrm{S}\right.$ e $\left.52,00^{\circ} \mathrm{W}\right)$. Os parâmetros meteorológicos analisados foram a visibilidade, 0 vapor de água precipitável e 0 ozônio. Estes parâmetros são os maiores responsáveis na variação da irradiância espectral (GREGG; CARDER, 1990).

Nas simulações realizadas (Tabela 1), a sensibilidade de um determinado parâmetro meteorológico é analisada mantendo-se os outros fixos nos seus respectivos valores médios. Os valores médios são os mesmos adotados por Gregg e Carder (1990): pressão atmosférica superficial $=1013,25 \mathrm{mb}$, tipo de massa de ar $(\mathrm{am})=1$ (predominância marinha); $U R \%=80 \%$; velocidade média do vento $=3 \mathrm{~ms}^{l} \mathrm{e}$ velocidade instantânea do vento $=5 \mathrm{~ms}^{l}$.

A irradiância descendente para cada banda $E_{d}(\lambda)$ do sensor SeaWiFS foi calculada através de

$E_{d}(\lambda)=\int_{\lambda_{i}}^{\lambda_{f}}\left[E_{d d}(\lambda)+E_{d s}(\lambda)\right] d \lambda ;$ 
centradas, respectivamente, em 412, 443, 490, 510,555 e $670 \mathrm{~nm}$. Os limites de integração são $\lambda_{i}=[407,438,485,505,550] \mathrm{e}$ $\lambda_{f}=\lambda_{i}+10$ e $d \lambda=1 \mathrm{~nm}$.

Para permitir uma comparação mais acurada do efeito de cada parâmetro meteorológico na estimativa da irradiância espectral descendente, foi calculada a diferença percentual em relação à situaçã̃o média (situação 1 na Tabela 1), que é a diferença entre as irradiâncias obtidas para situações extrema (máximo) e média, dividida pela irradiância da banda na situação média. Isto é:

diferença média percentual $=\left[\frac{\mathrm{E}_{\mathrm{d}}(\text { extremo) })-\mathrm{E}_{\mathrm{d}}(\text { média })}{\left.\mathrm{E}_{\mathrm{d}} \text { (média }\right)}\right] \times 100 \%,($

Tabela 1 - Sete simulações utilizando diferentes valores para os parâmetros atmosféricos analisados na estimativa da irradiância espectral descendente. VA: vapor de água precipitável ( $\mathrm{cm}$ ), $\mathrm{O}_{3}$ : ozônio (unidades Dobson - DU) e Vis.: visibilidade $(\mathrm{km})$.

Table 1 - Seven different combinations of input values for atmospheric parameters for estimate of downwelling spectral irradiance. VA: precipitable water vapor (cm), $\mathrm{O}_{3}$ : ozone concentration (Dobson unit - DU) and Vis.: visibility $(\mathrm{km})$.

\begin{tabular}{clccc}
\hline \hline & Situação & VA & $0_{3}$ & Visibilidade \\
\hline \hline 1 & Média & 2,6 & 275 & 17 \\
2 & Ḿ́nimo VA & 0,6 & 275 & 17 \\
3 & Máximo VA & 4,6 & 275 & 17 \\
4 & Mínimo O & 2,6 & 150 & 17 \\
5 & Máximo 0 & 2,6 & 400 & 17 \\
6 & Ḿ́nima Vis & 2,6 & 275 & 4 \\
7 & Máxima Vis & 2,6 & 275 & 50 \\
\hline \hline
\end{tabular}

\section{Dados de entrada para modelar a irradiância PAR}

0 modelo foi elaborado com a finalidade de calcular a irradiância $P A R$ recebida por uma superfície plana, de área unitária, ao longo do dia na cidade de Rio Grande. Os dados requeridos para a execução do modelo são: pressão atmosférica superficial, umidade relativa do ar, visibilidade, velocidade (média e instantânea) do vento, tipo de massa de ar, vapor de água precipitável e ozônio total.

Embora a irradiância tenha sido calculada ao longo do dia, os parâmetros atmosféricos de entrada do modelo foram mantidos constantes durante todo o dia. Os valores de pressão atmosférica superficial, umidade relativa do ar e visibilidade foram médias diárias disponíveis no Banco de Dados Meteorológicos da Fundação Universidade Federal do Rio Grande (FURG). 0 modelo requer a velocidade média das 24 horas anteriores e a velocidade instantânea (GREGG; CARDER, 1990). No entanto, como as medições disponíveis eram apenas as médias diá- rias, a velocidade média do dia anterior é considerada a velocidade média das 24 horas anteriores enquanto que a velocidade média do dia em questão é assumida como a velocidade instantânea.

Estes dados de velocidade são necessários para a seleçãa do tipo de massa de ar (GREGG; CARDER, 1990). 0 vapor de água precipitável foi determinado a partir da interpolação dos valores médios de janeiro e julho de 1990 (CRITCHFIELD, 1993). Desta forma, para latitude de $32^{\circ} \mathrm{S}$ e longitude de $52^{\circ} \mathrm{W}$, foram usados valores médios de vapor de água precipitável que variaram de $2,5 \mathrm{~cm}$ (inverno) a $3,1 \mathrm{~cm}$ (verão). A concentração de ozônio, quando mantida constante nas simulações, foi de 344 DU, derivada do modelo US Standard Atmospheric Model, mesmo valor usado por Bird (1984).

\section{AFERIÇÃO DO MODELO DE ATENUAÇÃO NA FAIXA DO PAR}

Observações concomitantes de dados atmosféricos (visibilidade, vapor de água e concentração de ozônio) e de irradiância espectral incidente na faixa do PAR, na superfície terrestre, para 0 ano de 1990, foram utilizados para verificar-se inicialmente a performance do mode10. As medições de irradiância $P A R$ foram tomadas por um quantumradiômetro LI-COR 1000 com coletor cosseno (sensor plano) em Rio Grande (ODEBRECHT, 1998). Apenas os dias cujo tempo de céu coberto foi menor que $15 \%$ da duração do dia foram considerados para a aferição do modelo, uma vez que o modelo admite céu totalmente livre de nuvens. 0 tempo de céu coberto foi obtido pela diferença entre a duração calculada do dia e o tempo de insolação diária, disponível no Banco de Dados Meteorológicos da FURG.

\section{RESULTADOS E DISCUSSÃO}

\section{Comparações entre dados observados e modelados na faixa do PAR}

Inicialmente, para verificar a importância dos constituintes atmosféricos na absorção e no espalhamento, o modelo foi executado considerando-se todas as transmitâncias iguais a l, ou seja: a atmosfera sendo absolutamente transparente. Neste caso, a irradiância espectral que chega na superfície terrestre não sofre influência dos constituintes atmostéricos. Como esperado, a irradiância $P A R$ modelada foi sempre maior que a medida (Figura 1).

Quando se considera toda a atenuaç̧ão espectral pela atmosfera, ou seja, calculando-se todas as transmitâncias, o modelo se aproxima da realidade (Figura 2). É importante salientar que as transmitâncias 


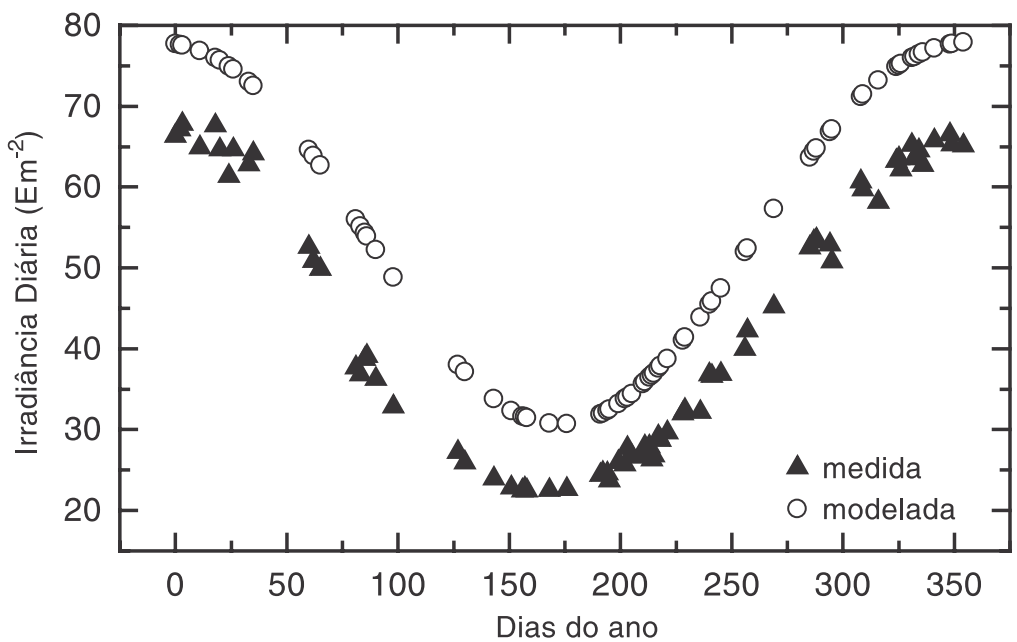

Figura 1 - Variação da irradiância PAR diária incidente na superfície terrestre ao longo do ano de 1990, para os dias cujo tempo de cobertura de nuvens era menor do que $15 \%$ da duração do dia. A atmosfera foi considerada totalmente transparente para a modelagem. Valores medidos estão representados por triângulos e os modelados por círculos.

Figure 1 - Variation of daily PAR irradiance incident on earth surface, for the days in 1990 which cloud cover time was shorter than $15 \%$ of day time. The atmosphere was considered totally transparent for the modeling. Measured values are represented by triangles and modeled ones by circles.

são calculadas espectralmente para cada ângulo solar, embora os parâmetros atmosféricos de entrada permaneçam constantes ao longo do dia. A irradiância PAR diária modelada acompanhou bem a variação ao longo do ano (Figura 2). 0 alto coeficiente de determinaçãa $\left(\mathrm{r}^{2}=0,988\right)$, com desvio-padrão de $1,74 \mathrm{E} \mathrm{m}^{-2}$, mostra que 0 modelo consegue excelente desempenho (Figura 3) para a variação ao longo do ano.

0 modelo consegue também estimar a variação da irradiância ao longo do dia. A Figura 4 mostra a irradiancia $P A R$ medida e modelada para os dias 12 de jutho, 7 de agosto, 15 de setembro, 16 de outubro, 22 de novembro e 16 de dezembro de 1990.

0 ozônio foi considerado por Gregg e Carder (1990) como um dos parâmetros mais importantes na estimativa da irradiância, podendo causar desvios de 13,2\% a $602 \mathrm{~nm}$ de comprimento de onda, onde a absorção do ozônio apresenta o valor mais alto para variações de ozônio de 100 a 600 DU. Neste trabalho, avaliamos a irradiância integrada em todo o espectro de $P A R$ e portanto, o provável desvio causado pelo valor fixo de 344 DU para 0 ozônio pode ter desaparecido durante a integração no intervalo da $P A R$. Outra possibilidade é o valor do ozônio para esta região estar muito próximo de $344 \mathrm{DU}$ a o longo de todo 0 ano de 1990, 0 que é bastante provável, permitindo um cálculo mais acurado da transmitância devido ao ozônio. No entanto, medidas de ozônio para a região de Santa Maria (RS), entre 1992 e 2002, mostraram valores médios entre 250 e 290 UD (PINHEIRO et al., 2003), o que está um pouco abaixo do valor médio adotado neste trabalho.

0 vapor de água precipitável foi avaliado por Gregg e Carder (1990) entre os limites de 0 a $5 \mathrm{~cm}$, correspondendo a uma amplitude de $5 \mathrm{~cm}$. Essa amplitude produziu um desvio percentual máximo de 20\% a $590 \mathrm{~nm}$ de comprimento de onda. Os valores de vapor de água precipitável usados nesta simulação, variaram entre 2,5 e $3,1 \mathrm{~cm}$ e portanto, a amplitude de variação analisada não passou de 0,6cm. Assim, é bastante razoável que, realmente, não tenha havido grande variação espectral na irradiância estimada por valores de vapor de água precipitável usados no presente artigo. Nesse caso, também é provável que o vapor de água estimado estivesse próximo do valor real, já que foi proveniente de um mapa médio de distribuição global de vapor de água precipitável (CRITCHFIELD, 1983).

\section{A influência dos parâmetros atmosféricos nas irradiâncias das faixas espectrais do SeaWiFS}

Visibilidade : em geral, para as seis bandas do SeaWiFS, verificou-se que a visibilidade altera significativamente a irradiância sobre a superfície terrestre, sendo que o seu efeito a 4km, situação de mínima visibi- 


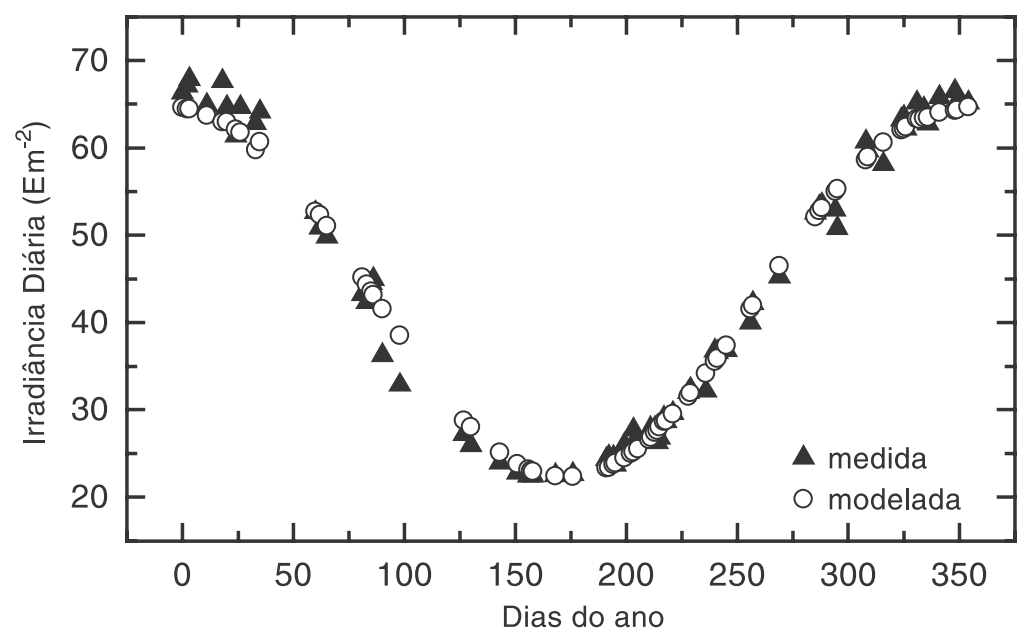

Figura 2 - Resultados da modelagem da irradiância PAR diária considerando a atenuação atmosférica para os mesmos dias de 1990 apresentados na Figura 1. Figure 2 - Model results of daily PAR irradiance considering atmospheric attenuation for the same days of 1990 shown in Figure 1.

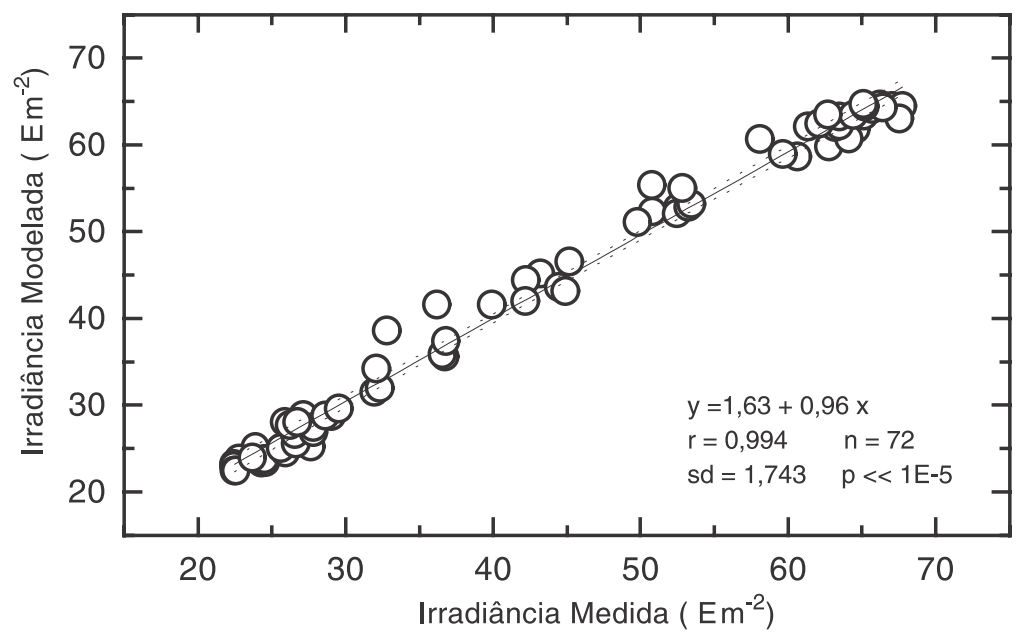

Figura 3 - Análise de regressão linear entre a irradiância PAR diária medida e a modelada da Figura 2.

Figure 3 - Linear regression analysis between measured and modeled PAR from Figure 2.

lidade, é muito maior que o seu efeito a 50 km, situação de máxima visibilidade, quando comparados ao efeito da visibilidade média de $17 \mathrm{~km}$ (figuras 5, 6 e 7). Gregg e Carder (1990) já haviam demonstrado que uma variação de $10 \mathrm{~km}$ em baixa visibilidade afetava muito mais do que a mesma variação em situação de boa visibilidade. Isto é: a diferença de 5 para $15 \mathrm{~km}$ de visibilidade é muito mais significativa que a variação de 35 a 45km de visibilidade. Assim, era esperado que a variação de 17 para $4 \mathrm{~km}$ de visibilidade (13 km de diferença) gerasse uma alteração muito maior na estimativa da irradiância do que a variação de 17 para $50 \mathrm{~km}$ (33km de diferença) (figuras 5 e 7). Embora tenham havido diferenças na estimativa da irradiância nas bandas do SeaWiFS com a variação da visibilidade, essa diferença foi pequena para todas as bandas. Numa variação da visibilidade de 4 a 50km, a maior diferença na irradiância ocorreu na banda $1(412 \mathrm{~nm})$ que, mesmo assim, não passou de $\sim 15 \mu \mathrm{W} \mathrm{nm} \mathrm{cm}^{-2}$ numa magnitude de $150 \mu \mathrm{W} \mathrm{nm} \mathrm{cm}^{-2}$. Em termos de diferença percentual em relação à situação média, a visi- 
bilidade não ultrapassou o limite de $\pm 20 \%$ em todas as bandas e ângulos solares, sendo que apenas em ângulos solares maiores do que $40^{\circ}$, a diferença percentual ultrapassou os $\pm 10 \%$ (Figura 6). A variação na diferença percentual da irradiância teve índice menor na do ângulo solar nos comprimentos de ondas menores, embora a diferença percentual em si tenha sido maior em ângulos solares menores e comprimentos de ondas menores. Isto significa que, para ângulos solares pequenos $\left(\theta<40^{\circ}\right)$, a variação da visibilidade afetou muito mais a estimativa da irradiância nos comprimentos de onda menores enquanto que em ângulos solares maiores $\left(\theta>60^{\circ}\right)$, a variação da visibilidade afetou muito mais a irradiância nos comprimentos de ondas maiores.

Ozônio : o parâmetro ozônio afetou muito pouco na irradiância estimada nas bandas do SeaWiFS, sendo nula na banda 1 (412 nm) (figuras 5 e 7). A variação na irradiância causada pelo ozônio foi tão pequena que as irradiâncias estimadas - usando-se valores máximo e mínimo de ozônio - quase se sobrepuseram ao valor da irradiância estimada com o valor médio de ozônio (situação 1). Pelas figuras 5 e 7, vê-se que a irradiância nas bandas do SeaWiFS manteve-se praticamente inalterada mesmo variando 0 ozônio de 150 a 400 DU. No entanto, pela diferença percentual (Figura 6), pode-se notar que a variação do ozônio alterou a irradiância. A diferença percentual em relação à situação média aumentou da banda 2 (443 nm) para a banda $5(555 \mathrm{~nm})$, com maior diferença percentual na banda 5 ( $555 \mathrm{~nm})$, e diminuiu um pouco na banda 6 $(670 \mathrm{~nm}) .0$ ozônio tem seu coeficiente de absorção aproximadamente entre 450 e $550 \mathrm{~nm}$, aumentando com o comprimento de onda, e, aproximadamente entre 630 e $700 \mathrm{~nm}$, diminuindo com o comprimento de onda (GREGG; CARDER, 1990). Entre 550 e $630 \mathrm{~nm}$, a absorção do ozônio é máxima. Como consequêencia, a Figura 6, ilustra claramente, que das seis bandas testadas, a banda $5(555 \mathrm{~nm})$ sofreu a maior alteração devido a variação do ozônio. № entanto, observa-se que a diferença percentual da irradiância nunca passou dos limites de $\pm 10 \%$ (nem mesmo na banda 5). As demais bandas apresentaram uma diferença percentual de $\pm 5 \%$, sendo que apenas nas bandas

\section{Ano 1990}
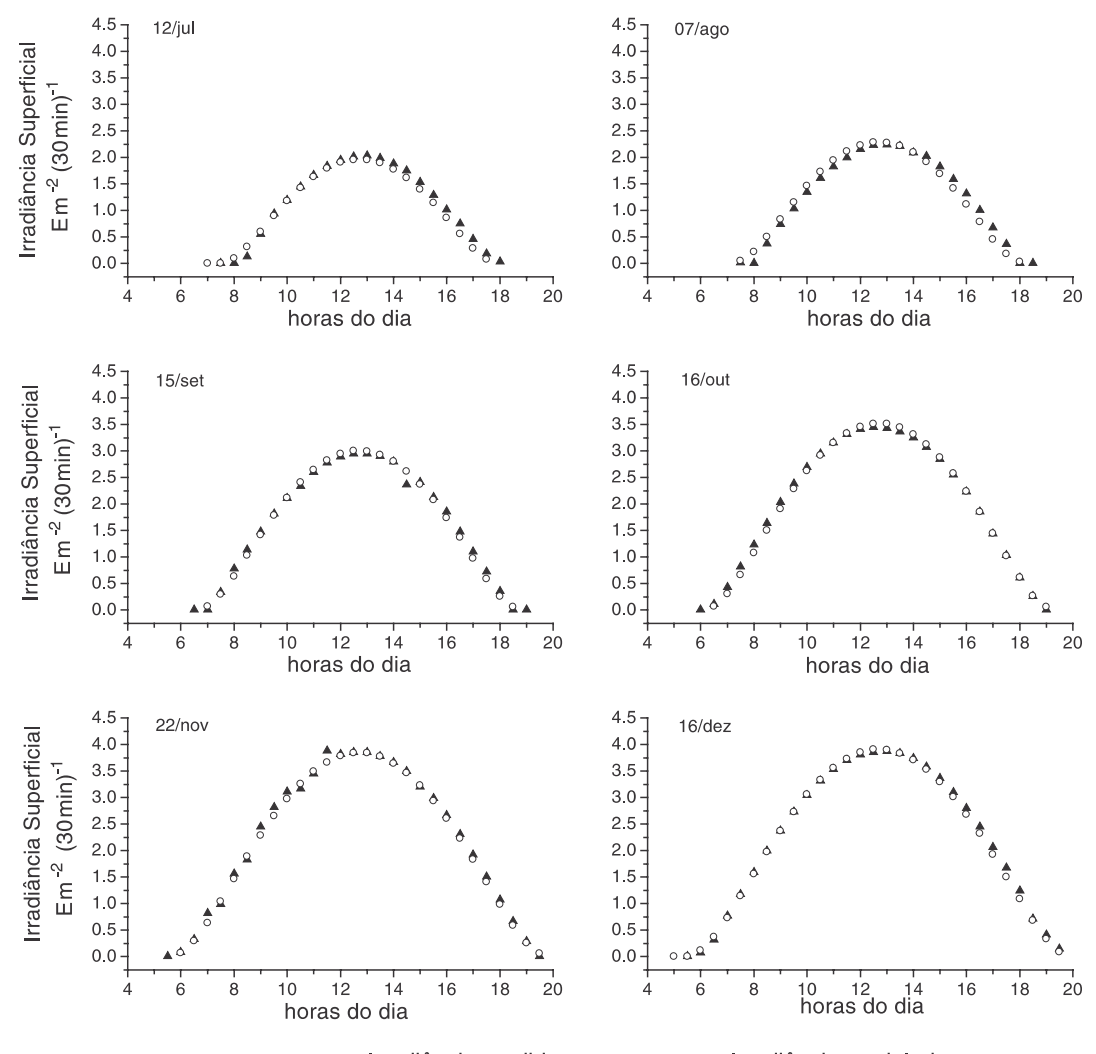

- Irradiância medida

Irradiância modelada

Figura 4 - Variação da irradiância PAR ao longo de alguns dias do ano de 1990. Valores medidos estão representados por triângulos e os modelados por círculos. Figure 4 - Daily variation of PAR throughout some days in 1990. Measured values shown in triangle and modeled ones in circle. 
$4(510 \mathrm{~nm})$ e $6(670 \mathrm{~nm})$ e em ângulos solares acima de $70^{\circ}$, a diferença percentual ultrapassou o limite de $\pm 3 \%$ que é bastante pequena. Vapor de água precipitável : 0 parâmetro vapor de água precipitável não apresentou diferenças nem no valor da irradiância (figuras 5 e 7), nem em termos de diferença percentual em relação à situação média
(Figura 6) nas cinco primeiras bandas do SeaWiFS. Mesmo na banda 6 $(670 \mathrm{~nm})$, a diferença foi praticamente imperceptível. A escolha das bandas do SeaWiFS foi baseada também nas janelas espectrais da atmosfera, incluindo a do vapor de água (HOOKER et al., 1992). Os resultados obtidos refletem isso, pois o coeficiente de absorção do vapor de
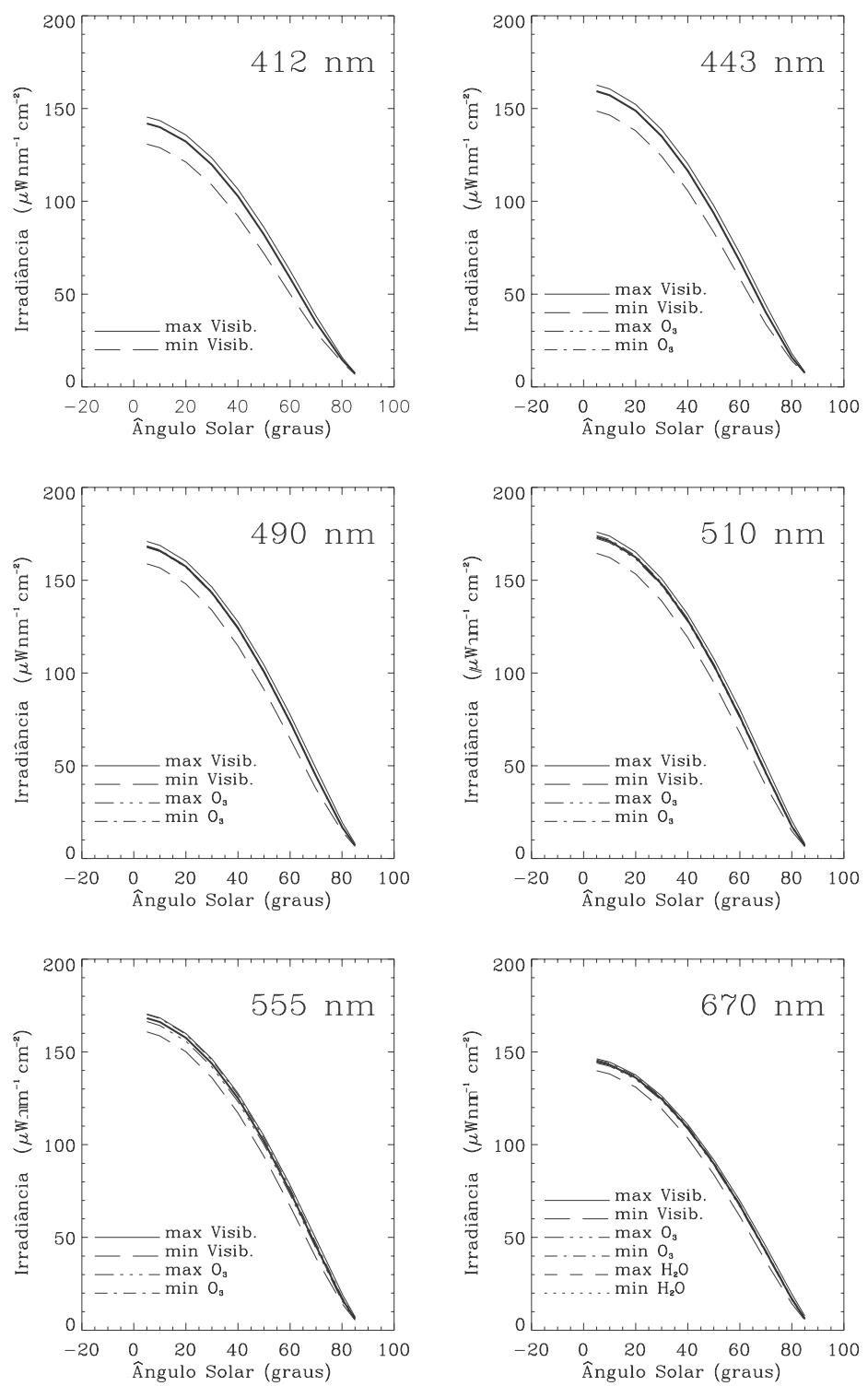

Figura 5 - Variação da irradiância $\left(\mu \mathrm{Wm}^{-1} \mathrm{~cm}^{-2}\right)$ incidente sobre a superfície terrestre nas bandas do SeaWiFS em diferentes situações meteorológicas em funcão do ângulo solar. A irradiância obtida pela situacão média está representada pela linha sólida mais grossa. Estão apresentadas apenas as irradiâncias obtidas das situaçōes extremas que diferiram da situação média.

Figure 5 - Variation of incident irradiance on the earth sufface at SeaWiFS bands in extreme meteorological conditions in function of solar angle. The modeled irradiance representing the average situation is shown in thick solid line. The graphics present only extreme conditions when the modeled irradiance differed from the average condition. 

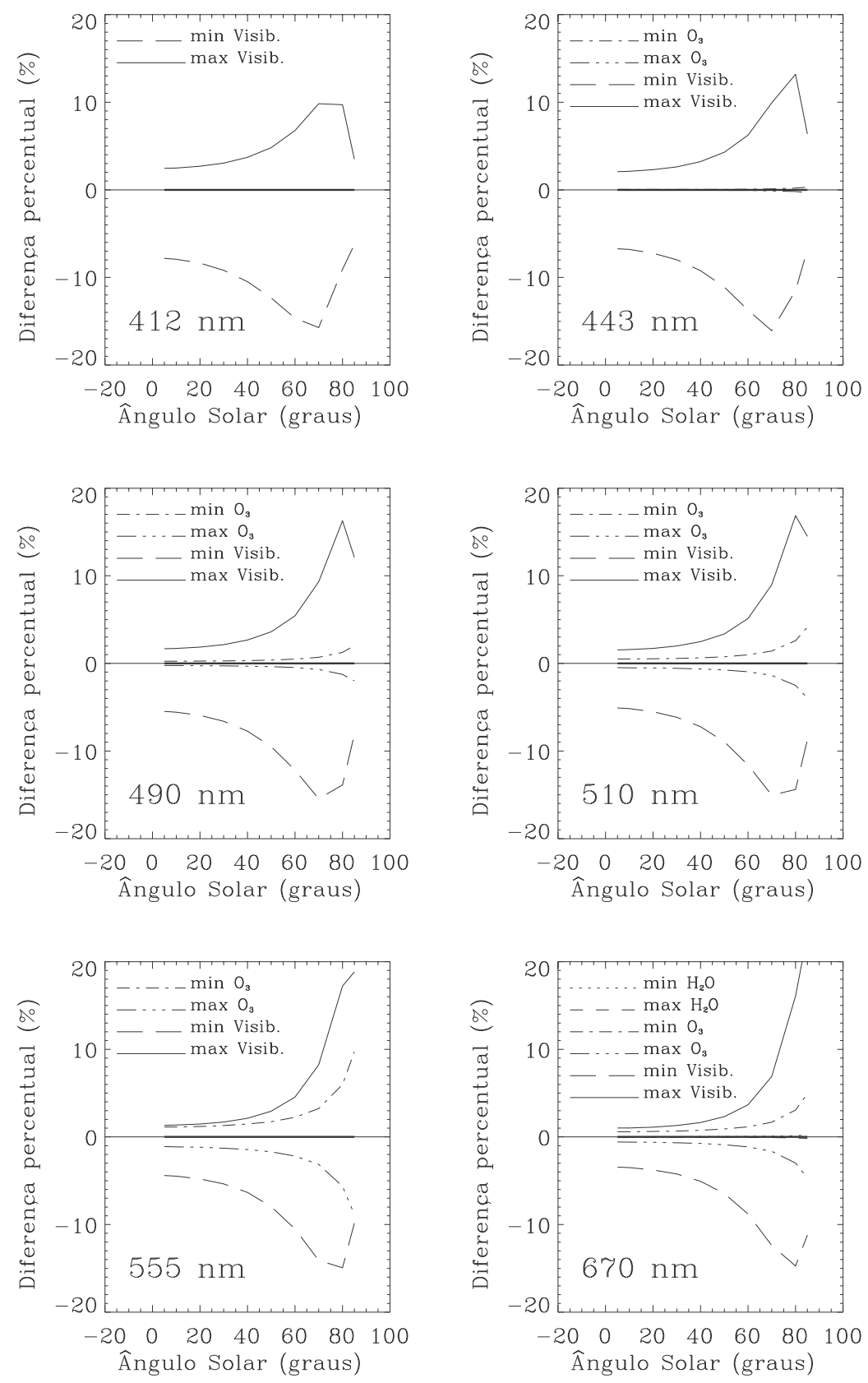

Figura 6 - Diferenças percentuais da irradiância espectral nas diferentes situações meteorológicas em relação à situaçãa média. Apenas as situações em que a diferença percentual foi não nula estão apresentadas.

Figure 6 - Difference between the spectral irradiances in a extreme condition and in the average condition weighted by the average condition. The graphics present only those conditions when the difference was bigger than zero. 

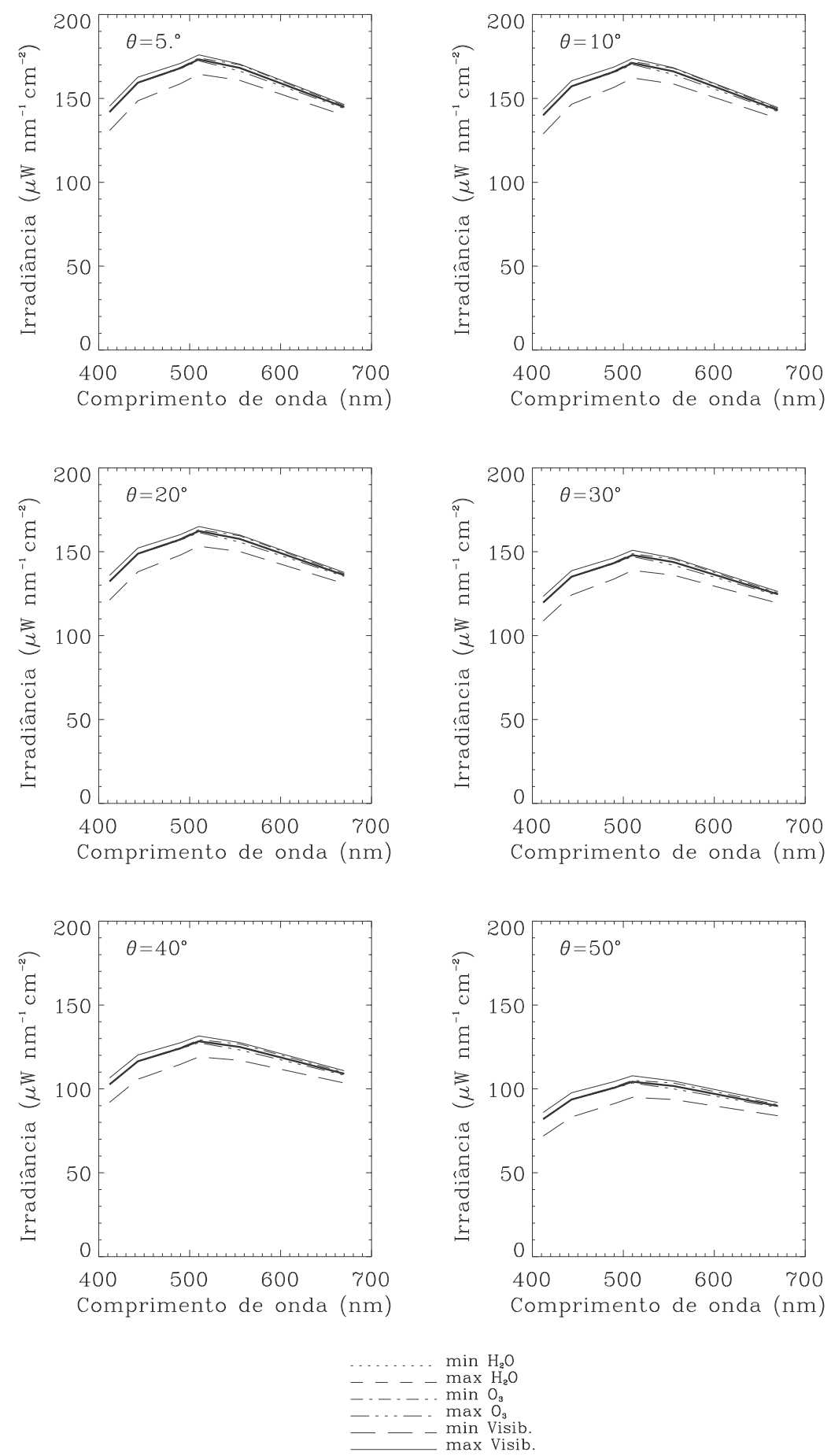

Figura 7 - Irradiância espectral modelada $\left(\mu W \mathrm{~nm}^{-1} \mathrm{~cm}^{-2}\right)$, em função do comprimento de onda, para diferentes ângulos solares, considerando as condições atmostéricas estipuladas pela Tabela 1.

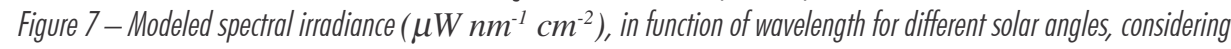
the atmospheric conditions shown in Table 1. 

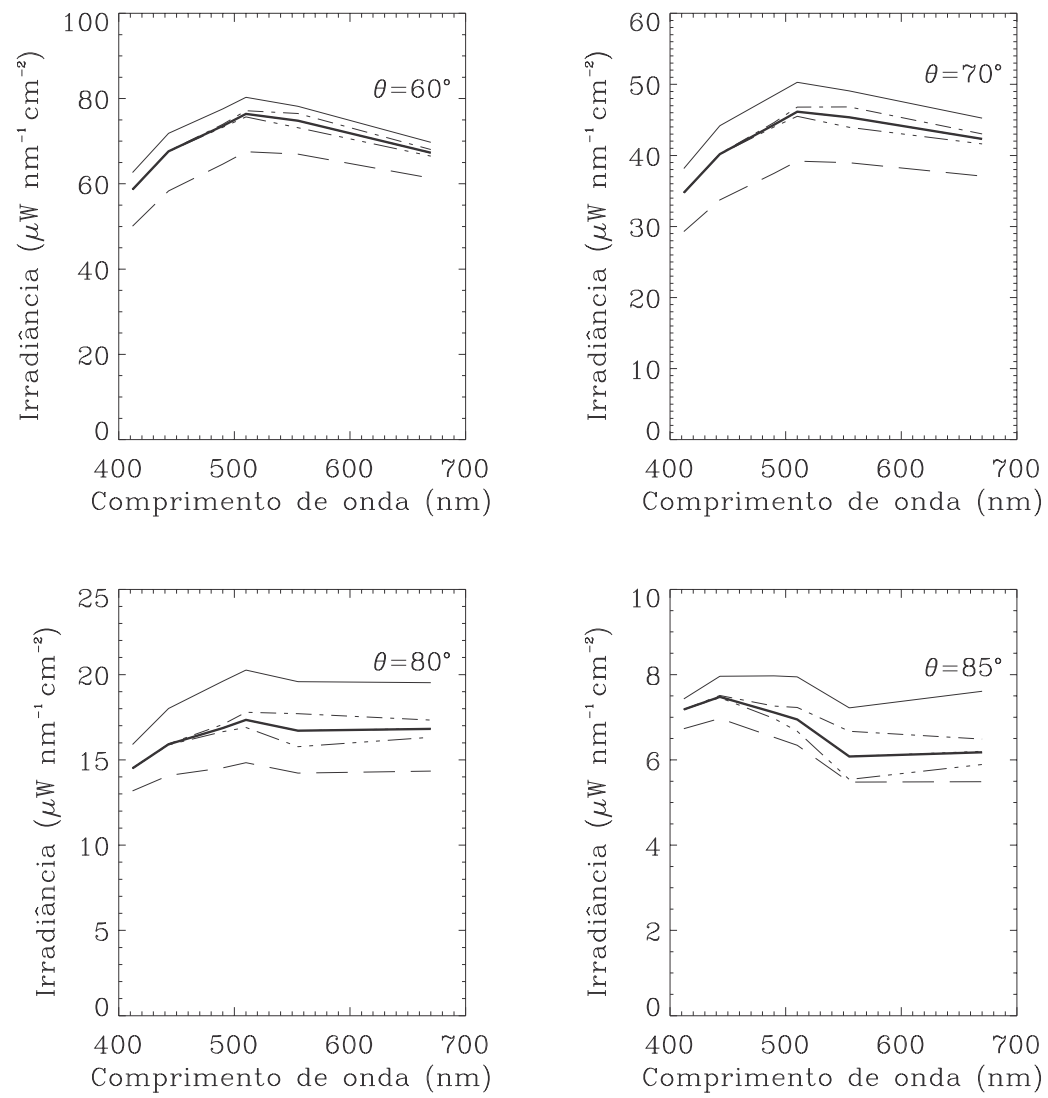

$$
\begin{aligned}
& \text {........ min } \mathrm{H}_{2} \mathrm{O} \\
& \text { - }-\ldots \max \mathrm{H}_{2} \mathrm{O} \\
& \ldots \ldots \min \mathrm{O}_{3} \\
& \text {-... }-\max 0 \\
& \text { — - - min Visib }
\end{aligned}
$$

Figura 7 (Cont.) - Irradiância espectral modelada $\left(\mu W \mathrm{Nm}^{-1} \mathrm{~cm}^{-2}\right)$, em função do comprimento de onda, para diferentes ângulos solares, considerando as condições atmosféricas estipuladas pela Tabela 1.

Figure 7 (Cont.) - Modeled spectral irradiance $\left(\mu \mathrm{W} \mathrm{nm}^{-1} \mathrm{~cm}^{-2}\right)$, in function of wavelength for different solar angles, considering the atmospheric conditions shown in Table 1. 
água precipitável apresenta-se praticamente nulo nas bandas do SeaWiFS.

\section{A influência dos parâmetros atmosféricos nas irradiâncias nas razões entre bandas do SeaWiFS}

Nos algoritmos empíricos para a determinação da concentração de clorofila $a$, é normalmente utilizada a razão entre reflectâncias de duas bandas, $R_{i j^{\prime}}$ dada por:

$$
R_{i j}=\frac{L_{w}\left(\lambda_{i}\right)}{L_{w}\left(\lambda_{j}\right)} \times \frac{E_{d}\left(\lambda_{j}\right)}{E_{d}\left(\lambda_{i}\right)}
$$

onde as irradiâncias espectrais descendentes nas bandas $\lambda_{j}$ são calculadas pelo modelo. Denominando $E_{d}\left(\lambda_{j}\right) / E_{d}\left(\lambda_{i}\right)$ de razão entre irradiâncias $\left(R_{E d} i j\right)$ sua análise permitirá avaliar os efeitos que os parâmetros atmosféricos exercem sobre os algorítimos bio-óticos. Importante observar que a raz̃ão $L_{w}\left(\lambda_{j}\right) / L_{w}\left(\lambda_{i}\right)$ depende dos constituintes da água como substâncias orgânicas dissolvidas, material particulado inorgânico e orgânico suspensos, entre outros fatores (PRIEUR; SATHYENDRANATH, 1981; AIKEN et al., 1995). Mas os fatores que afetam a raz̃̃o $L_{w}\left(\lambda_{j}\right) / L_{w}\left(\lambda_{i}\right)$ não são analisados neste artigo. Analisamos 0 quanto visibilidade, ozônio e vapor de água precipitável afetam em quatro das razões entre irradiâncias das bandas do SeaWiFS: raz̃̃o entre as bandas $3(490 \mathrm{~nm})$ e $4(510 \mathrm{~nm}), R_{E d} 34$; raz̃̃o entre as bandas $2(443 \mathrm{~nm})$ e $5(555 \mathrm{~nm}), R_{E d} 25$; raz̃ão entre as bandas 3 $(440 \mathrm{~nm})$ e $5(555 \mathrm{~nm}), R_{E d} 35$; razão entre as bandas $4(510 \mathrm{~nm}) \mathrm{e}$ $5(555 \mathrm{~nm}), R_{E d} 45$.

As variações na irradiância espectral causadas pela variação dos parâmetros atmosféricos resultaram em pouco efeito nas razões entre irradiâncias das bandas (figuras 8 e 9) usadas nos algoritmos empíricos da cor do oceano, até aproximadamente $70^{\circ}$ de ângulo solar, pois o uso de razões entre bandas tem a vantagem de compensar parcialmente 0 efeito atmosférico e a magnitude da radiação solar que chega na superfície da água (GORDON et al., 1980).

Dessa forma, mesmo que a variação nos parâmetros atmostéricos tenha causado diferenç̧as na irradiância nas bandas do SeaWiFS, praticamente, não houve diferenças nas razões entre bandas, $R_{E d} i j$. A variação do vapor de água precipitável não afetou em nada a razão entre bandas e por isso, foi omitido das figuras $8 \mathrm{e} 9$. De uma maneira geral, as razões entre bandas, até $70^{\circ}$ de ângulo solar, apresentaram diferenças percentuais baixas em relação à média, sendo que a $R_{E d} 25$ apresentou as maiores variaç̧ões. Note-se que mesmo a $R_{E d} 25$ apresentou diferenças percentuais pequenas, pois mesmo a $70^{\circ}$ de ângulo solar, não passou de $\pm 4 \%$ (Figura 9). Estas diferenças, relativamente maiores, nos percentuais, começaram a ocorrer a partiri de $70^{\circ}$ de ângulo solar. Essa razão entre bandas foi usada para processar as imagens CZCS, mas não é a que apresenta melhores resultados porque a banda 2 (443 $\mathrm{nm}$ ) é bastante afetada por matéria orgânica dissolvida na água do mar (AIKEN et al., 1995).

No outro extremo, a razão $R_{E d} 34$ apresentou-se praticamente inalterada com a variação do ozônio ou da visibilidade e praticamente constante entre 0,96 e 0,97 de 5 a 80 de ângulo solar (Figura 8). Pode-se concluir que nas sete situações atmosféricas analisadas, a $R_{E d} 34$ permaneceu praticamente constante, apresentando diferenças percentuais sempre em torno de $\pm 2 \%$, mesmo no ângulo solar de $85^{\circ}$ (Figura 9). A distância entre as bandas desta razão é de apenas $20 \mathrm{~nm}$ e assim, 0 efeito da variação dos parâmetros atmosféricos foi praticamente de mesma magnitude nas duas bandas. Sendo a variação de mesma magnitude, quando se fez a raz̃a entre elas, a magnitude foi praticamente anulada resultando numa pequena variação na razão entre bandas. Embora as bandas $3(490 \mathrm{~nm})$ e $4(510 \mathrm{~nm})$ estejam tão próximas, de tal modo que a razão entre as irradiâncias se mantém praticamente constante, a $R 34$ apresenta grande importância na estimativa da concentração de clorofila $a$, através de modelos empiricos, já que a banda $3(490 \mathrm{~nm})$ é onde os carotenóides possuem alta absorção. Como os carotenóides e a clorofila $a$ apresentam alta correlação de coocorrência e covariância, a estimativa da concentração de clorofila a usando a razão $R 34$ resulta em boas estimativas (AIKEN et al., 1995). Estes autores mostraram que quando se usa a banda $4(510 \mathrm{~nm})$ no denominador, quanto maior for o comprimento de onda do numerador, melhor resultado é obtido na relação entre razão entre bandas e concentração de clorofila $a$.

A razão $R_{E d} 35$, na situaç̧ão média (situação 1) de parâmetros atmosféricos (Figura 8), até os $40^{\circ}$ de ângulo solar, apresentou valores próximos de 1, com uma ligeira diminuição para ângulos solares maiores e chegando a 0,98 aos $70^{\circ}$. Como para obter a razão entre reflectâncias das bandas, necessária para analisar os modelos bio-óticos, multiplica-se $\left(R_{E d} 35\right)^{-1}$ por $R_{L u} 35$ (Equuação 17), se o valor do ozônio estiver próximo de $275 \mathrm{DU}$ e a visibilidade entre 17 e $50 \mathrm{~km}$, não é necessário nem mesmo estimar $E d$ para ângulos solares menores do que $40^{\circ}$. Pode-se assumir como razão entre bandas das reflectâncias apenas o valor de razão entre as radiâncias espectrais, eliminando assim 0 esforço da modelagem. Este resultado é bastante animador, pois a $R 35$ é a razão entre bandas mais usada atualmente em modelos bio-óticos empiricos e que apresentou melhores resultados até o momento (AIKEN et al., 1995; 0'REILLY et al., 1998).

A razão $R_{E d} 45$ apresentou-se praticamente constante até os $40^{\circ}$ de ângulo solar, para situação média e de máxima visibilidade 


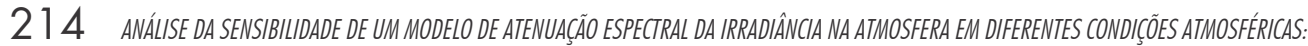
UMA APLICAÇÃO PARA O Sea-viewing Wide Field-of-view Sensor (SeaWiFS)
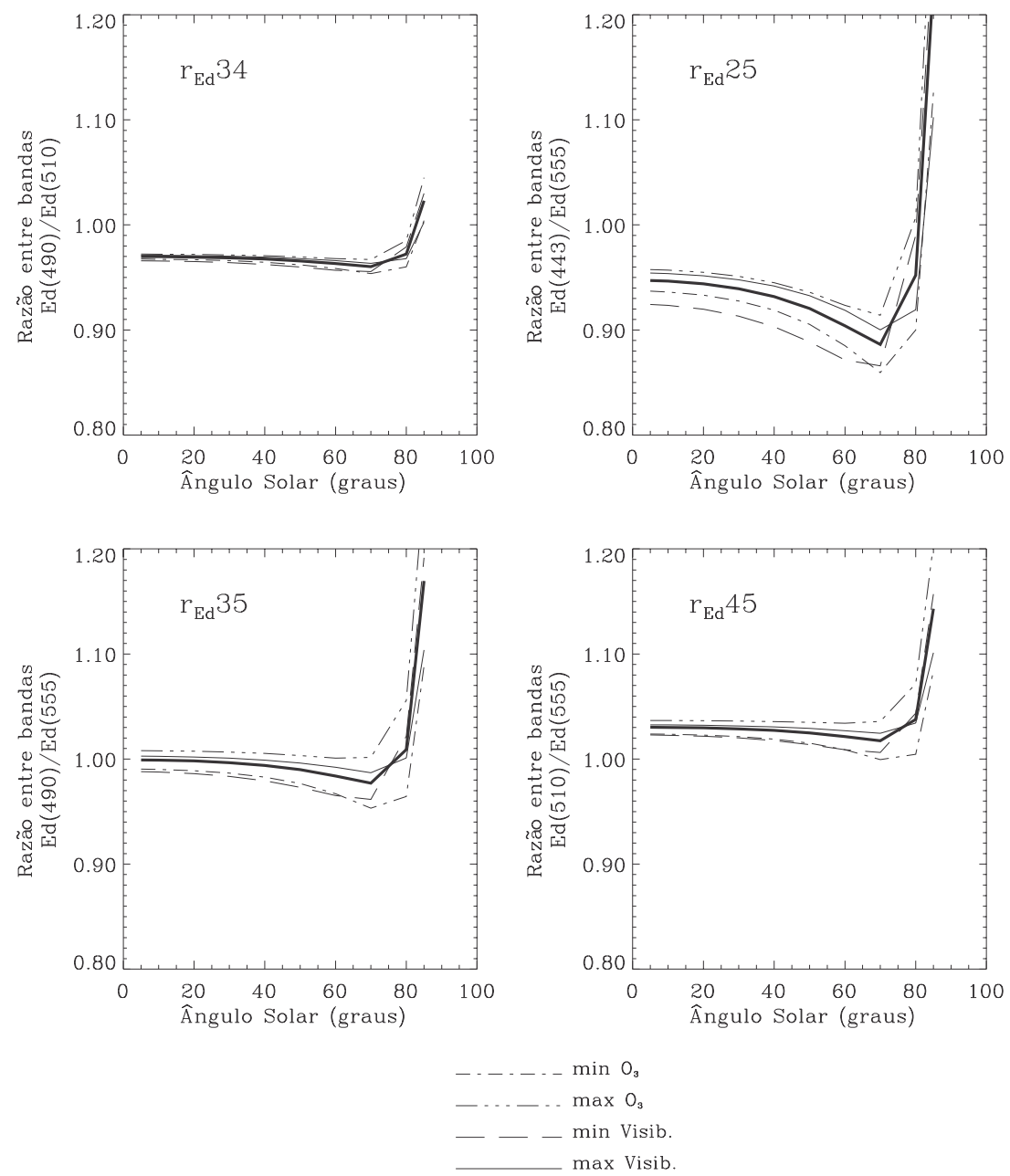

Figura 8 - Razão entre irradiâncias nas bandas do SeaWiFS modeladas em situações extremas de visibilidade e de concentrações de ozôniio.

A razão entre irradiâncias da situacçoo média está representada pela linha sólida mais grossa.

Figure 8 - SeaWiFS band ratios modeled in extreme conditions of visibility and ozone.

The band ratio in the average condition is shown in thick solid line.

$\left(R_{E d} 45=1,03\right)$, na situação de máximo ozônio $\left(R_{E d} 34=1,04\right)$ até os $70^{\circ}$ de ângulo solar (Figura 8). Esta razão relaciona-se com a concentração de clorofila a porque os carotenóides, altamente correlacionados à clorofila, têm alta absorção na banda $4(510 \mathrm{~nm})$ (AIKEN et al., 1995). A $R 45$ também foi usada para explicar partes da relação entre a cor do oceano e a concentração de clorofila a que outras razões, como a $R 35$, não conseguiram explicar (CalCOFI três bandas $O^{\prime}$ REILLY et al., 1998).

De uma maneira geral, verificamos que a variação aos valores extremos de visibilidade e de ozônio afetou muito pouco nas quatro razões entre bandas aqui analisadas e a diferença percentual das razões entre bandas manteve-se sempre entre $\pm 10 \%$ para todos os ângulos solares (Figura 9). Com exceção da $R_{E d} 25$, até aproximadamente $60^{\circ}$ de ângulo solar, todas as razões entre bandas apresentaram diferenças percentuais, menores que $\pm 2 \%$. Esta exceçãa é explicada pelo fato das bandas $2(443 \mathrm{~nm})$ e $5(555 \mathrm{~nm})$ estarem mais distantes que nas combinações $3(490 \mathrm{~nm})$ e $4(510 \mathrm{~nm})$, na $3(490 \mathrm{~nm})$ e $5(555 \mathrm{~nm})$ e na $4(510 \mathrm{~nm})$ e 5 (555 nm) (Figura 9).

Analisando-se a influência dos parâmetros atmosféricos na razão da irradiância entre bandas (Figura 9), com exceção da $R_{E d} 25,0$ 

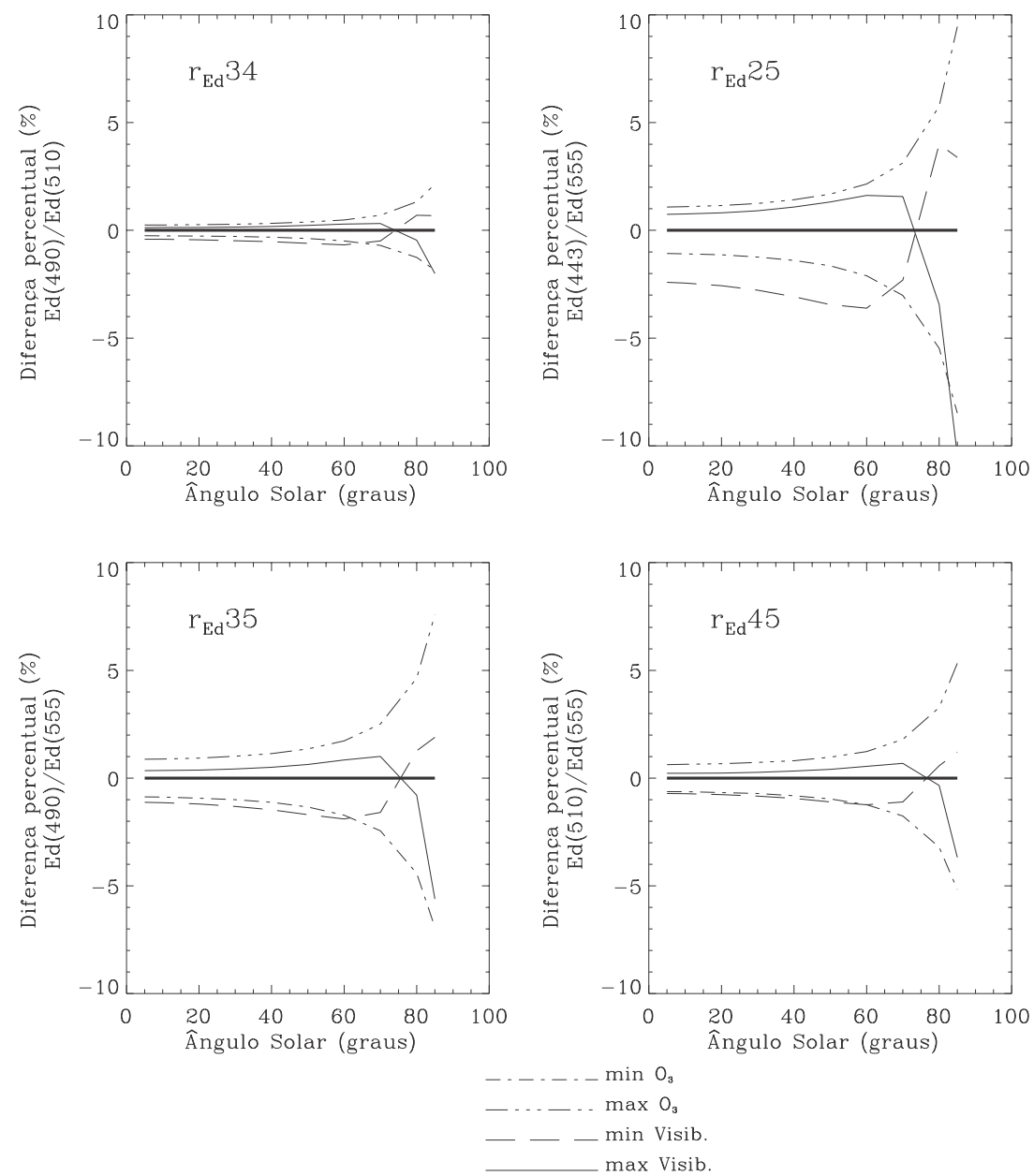

Figura 9 - Diferença percentual entre as razões entre irradiâncias modeladas em situação extrema e em situação média. Figure 9 - Difference between the band ratios in extreme condition and in the average condition weighted by the average condition.

ozônio mostrou-se mais importante do que a visibilidade nesta amplitude de variação dos parâmetros atmosféricos (Tabela 1), mesmo que a visibilidade tivesse afetado mais na irradiância espectral (figuras 5, 6 e 7). Na Figura 7 , a partir do ângulo solar de $60^{\circ}$, a irradiância, calculada com concentraçỗes de ozônio extremas, começa a se distanciar da irradiância calculada com parâmetros médios, alterando bastante a variação na magnitude da irradiância ao longo do comprimento de onda. Essa diferença na magnitude, ao longo do comprimento de onda é muito mais importante do que a simples variação da irradiância quando se considera a razão entre bandas.
A visibilidade causou pequenas diferenças percentuais nas razões entre bandas e quase constante com a variação do ângulo solar (Figura 9). Isto ocorreu porque embora a visibilidade tivesse causado maior diferença na irradiância, a atenuação foi praticamente nãoespectral com a variação do ângulo solar, causando uma variação na magnitude da irradiância em todo o espectro visível (Figura 7). Assim, as diferenças nas magnitudes não influenciaram a razão entre bandas. No entanto, a partir dos $60 \sim 70^{\circ}$ de ângulo solar, a forma do espectro de irradiância muda completamente, aumentando a irradiância nos com- 
primentos de onda maiores (Figura 7). Esta é a principal causa da grande diferença percentual da razão entre irradiâncias $R_{E d} 25$.

Deve-se considerar que todas as análises foram realizadas assumindo condições de céu limpo, sem cobertura de nuvens. Bartlett e outros (1998) analisaram diferentes frações de cobertura de nuvens atuando na irradiância espectral descendente e 0 quanto essa atenuação espectral da nuvem poderia afetar a estimativa da concentração de clorofila $a$. Esses autores estimaram a concentração de clorofila a sob diferentes condições de cobertura de nuvens, usando a razão entre bandas $\operatorname{Rrs}(440) / \operatorname{Rrs}(560)$. A diferença percentual entre a concentração de clorofila $a$ estimada assumindo 0 efeito espectral da nuvem sobre 0 espectro de luz descendente, e a concentração de clorofila $a$ estimada assumindo irradiância sem efeito das nuvens, foi praticamente nula para fração de cobertura de nuvens menor que 20\% e só ultrapassando $5 \%$ de diferença percentual em fração de cobertura maior que $50 \%$. A cobertura total de nuvens causou uma diferença percentual de $\sim 30 \%$ na estimativa da concentração de clorofila $a$. Estes autores ainda conclúiram que a atenuação espectral da nuvem varia de local para local e 0 modelo obtido por eles para a região de Halifax (Canadá) é diferente do obtido por Siegel e outros. (1998) para a região do Mar de Bering.

\section{CONCLUSÕES}

Neste trabalho, procurou-se analisar a sensibilidade de um modelo de irradiância espectral incidente sobre a superfície do mar, sob diferentes condições atmosféricas. Tendo em vista os resultados de Gregg e Carder (1990), os seguintes parâmetros atmosféricos foram analisados: visibilidade, vapor de água precipitável e ozônio. Os resultados obtidos na estimativa da irradiância nas bandas do SeaWiFS mostraram claramente a importância de se conhecer, previamente, valores de visibilidade e concentração de ozônio, enquanto que 0 vapor de água precipitável praticamente não causa interferência.

Entretanto, essas simulações demonstraram que apesar de serem relevantes na determinação de irradiância espectral, em alguns casos, os parâmetros atmosféricos podem ser padronizados, isto é, dados médios podem ser usados para obtenção de razões entre reflectâncias das bandas do SeaWiFS.

Embora a variação da visibilidade tenha afetado mais a estimativa da irradiância, a variação do ozônio causou maior diferença na estimativa da razão entre irradiâncias. Portanto, é necessário que se tenha conhecimento do valor da concentração de ozônio quando usar este modelo no cáculo da razão entre reflectâncias nas bandas do SeaWiFS. 0 ozônio é mapeado atualmente por sensores remotos e as concentraçōes de $\mathrm{O}_{z}$ em escala global, estão disponíveis pela Internet. ${ }^{3}$ Além disso, o monitoramento da concentração de ozônio na atmosfera, em escala regional, vem sendo feito por vários laboratórios (PINHEIRO et al, 2003).

No cálculo da razão entre bandas $R 34, R 35$ e $R 45$ até os $60^{\circ}$ de ângulo solar, 0 uso de modelo de atenuação de Gregg e Carder (1990) na estimativa da irradiância necessária ao cálculo da razão entre bandas da reflectância, é fortemente recomendado usando parâmetros atmosféricos da situação média (situação 1) analisados no presente trabalho. Como já recomendado antes, é importante que se tenha pelo menos noção dos valores de visibilidade e ozônio. No entanto, quando a raz̃o entre bandas é a $R 34$, com visibilidade entre 4 e $50 \mathrm{~km}$ (o que ocorre na maioria das vezes), pode-se tomar como valor de $R_{E d} 34$ sendo igual a 0,965 , que é bastante próximo do modelado. Nos casos de $R 35$ e da $R 45$, conhecendo-se o ângulo solar e os valores aproximados de visibilidade e de ozônio, pode-se obter o valor de $R_{E d}$ através da Figura 8.

№ entanto, deve-se observar que apenas variações de visibilidade, vapor de água precipitável e ozônio foram analisadas, considerando condições de céu sem cobertura de nuvens. Assim, estudos locais de atenuação espectral, com presença de nuvens, devem ser realizados para aumentar a confiabilidade na estimativa de $R_{E d}$.

Deve-se ainda considerar o fato de que o sensor SeaWiFS mapeia 0 oceano aproximadamente ao meio dia local, dependendo da órbita; logo, 0 ângulo solar depende muito da latitude. Para regiões equatoriais e tropicais, o modelo apresenta grande valia, pois o ângulo solar será pequeno. Para regiões temperadas, o ângulo solar dependerá também da época do ano.

\section{Agradecimentos}

Os autores agradecem ao Laboratório de Oceanografia Física/ FURG e ao CEPSRM/UFRGS, por apoiarem a realização deste trabalho. Claudia Omachi recebeu apoio financeiro da Coordenação de Aperfeiçoamento de Pessoal de Nível Superior (CAPES), através da bolsa de mestrado.

\footnotetext{
Disponível em: < http://toms.gsfc.nasa.gov> .
} 


\section{REFERÊNCIAS}

AUSTIN, R.W. Inherent spectral radiance signatures of the ocean surface. In: DUNTLEY, S. Q. et al. Ocean color analysis. La Jolla: Scripps Institution of Oceanography, 1974.

BARTLETT, Y. S. et al. The spectral effects of clouds on solar irradiance. Journal of Geophysical Research, [S.I.], v. 103, n. C13, p. 31017-31031, 1998.

BEHRENFELD, M. J. et al. Biospheric primary production during an ENSO transition. Science, [S.I.], v. 291, p. 2594-2597, 2001.

BIRD, R. E. A simple solar spectral model for direct-normal and diffuse horizontal irradiance. Solar Energy, [S.I.], v. 32, n. 4, p. 461-471, 1984. ; RIORDAN, C. Simple solar spectral model for direct and diffuse

irradiance on horizontal and tilted planes at the earth's surface for cloudless atmospheres. Journal of Climate and Applied Meteorology, [S.I.], v. 25, p. 87-97, 1986.

CLARKE, G .L.; EWING, G. C; LORENZEN, C. J. Spectra of backscattered light from the sea obtained from aircraft as a measure of chlorophyll concentration. Science, [s.I.], v. 167, p. 1119-1121, 1970.

CRITCHFIELD, H. J. General Climatology. [S.I.]: Prentice-Hall, 1983.

GARCIA, C. A. E.; GARCIA, V. M. T. Bio-optical measurements in the Southwestern Atlantic and Southern Oceans for chlorophyll-a concentration mapping from space. In: OCEAN OPTICS, 16., 2002, Santa Fe. Anais... Santa Fe: [s.n.], 2002.

GORDON, H. R. et al. Phytoplankton pigments from the Nimbus-7 Coastal Zone Color Scanner: comparisons with surface measurements. Science, [S.I.], v. 210, p. 63-66, 1980.

GREGG, W. W.; CARDER, K. L. A simple spectral solar irradiance model for cloudless maritime atmospheres. Limnology and oceanography, [S.I.], v. 35, n. 8, p. 1657-1675, 1990.

HOOKER, S.B.; FIRESTONE, E. R. (Ed.). An overview of SeaWiFS and ocean color. NASA Technical Memorandum 104566, Greenbelt, v. 1, jul. 1992.

The Sea WiFS CZCS-type pigment algorithm. NASA Technical Memorandum 104566, Greenbelt, v. 29, p. 9-14, jun. 1995.
HOVIS, W. A. et al. Nimbus-7 Coastal Zone Color Scanner: system description and initial imagery. Science, [S.I.], v. 210, p. 60-63, 1980. INTERNATIONAL OCEAN COLOUR COORDINATING GROUP. Minimum requirements for an operational ocean-color sensor for the open ocean. Report of the International Ocean-Color Coordinating Group, Villefranchesur-mer, 1998. n. 1.

KASTEN, F. A new table and approximate formulae for relative optical air mass. Arch. Meteorol. Geophys. Bioklimatol, [S.I.], n. B14, p. 206-223, 1966.

KIRK, J. T. O. Light and photosynthesis in aquatic ecosystems. Cambridge: Cambridge University Press, 1994.

MITCHELL, B. G. Coastal Zone Color Scanner retropective. Journal of Geophysical Research, [s.I.], v. 99, n. C4, p. 7291-7292, 1994.

ODEBRECHT, C. Radiação fotossinteticamente ativa em Rio Grande, RS. Documentos Técnicos em Oceanografia, Rio Grande, 1998. v. 8.

O'REILLY, J. E. et al. Ocean color chlorophyll algorithms for SeaWiFS. Journal of Geophysical Research, [S.I.], v. 103, n. C11, p. 24937-24953, 1998.

PALTRIDGE, G. W.; PLATT, C. M. R. Radiative processes in meteorology and climatology. Amsterdam: Elsevier Science, 1976.

PINHEIRO, D. K. et al. Monitoramento do ozônio atmosférico e radiação ultravioleta no observatório especial do sul. In: WORKSHOP GRUVS, 2003, Rio Grande. Radiação UV no Sul do Brasil: síntese do conhecimento. Rio Grande: Fundação Universidade do Rio Grande, 2003. p. 7.

PRIEUR, L.; SATHYENDRANATH, S. An optical classification of coastal and oceanic waters based on the specific spectral absorption curves of phytoplankton pigmets, dissolved organic matter, and other particulate materials. Limnology and Oceanography, [S.I.], v. 26, n. 4, p. 671689, 1981.

SIEGEL, D. A.; WESTBERRY, T. K.; OHLMANN, J. C. Cloud color and ocean radiant heating. Journal of Climate, [S.I.], v. 12, n. 4, p. 1101-1116, 1999.

SPENCER, J. W. Fourier series representation of the position of the sun. Search, [S.I.], v. 2, p. 172, 1971. 


\section{NOTAS SOBRE OS AUTORES}

Claudia Yuki Omachi é doutora em Ciências Marinhas pela Universidade de Plymouth, Reino Unido (2003), mestre em Sensoriamento Remoto pela UFRGS (1999) e oceanóloga pela FURG (1997). Atua em oceanografia biológica de larga escala, através do sensoriamento da cor do oceano, das províncias oceânicas e da fluorescência aplicada à fisiologia e produção primária do fitoplâncton marinho. Recentemente, a bio-óptica, fisiologia e toxinas das florações de microalgas em regiões costeiras e de maricultura têm sido alvos de sua pesquisa.

Carlos Alberto Eiras Garcia é doutor (1989) e mestre (1986) pela Universidade de Southampton, Inglaterra e físico formado pela UNICAMP (1977). Em 1979, foi contratado como professor da FURG. Desde 1990, trabalha como professor e pesquisador em Oceanografia Física e Oceanografia por Satélite no Departamento de Física da FURG. Também foi chefe do Departamento de Física (1994-1997) e reitor da FURG (1997-2000). Suas atividades incluem aulas, pesquisa e orientação de estudantes de graduação e pós-graduação. Pesquisa desde 1980 a cor do oceano e atualmente, coordena 0 Grupo de Oceanografia de Altas Latitudes no Oceano Antártico dentro do Programa Antártico Brasileiro. 